\title{
Mathematical Description and Modelling of Transportation of Cargoes on the Base Digital Railway
}

\author{
Natalia Zhuravleva \\ Transport economy Department \\ Emperor Alexander I St. Petersburg \\ State Transport University \\ St. Petersburg, Russia \\ zhuravleva_na@mail.ru
}

\author{
Ilia Guliy \\ Transport economy Department \\ Emperor Alexander I St. Petersburg \\ State Transport University \\ St. Petersburg, Russia \\ ilya.guliy@mail.ru
}

\author{
Mark Polyanichko \\ Department of Information Technology \\ and IT Security \\ Emperor Alexander I St. Petersburg \\ State Transport University \\ St. Petersburg, Russia \\ polyanichko@pgups.ru
}

\begin{abstract}
This article presents the results of a mathematical description of the transportation process of goods by rail on the exit routes. The parameters reflecting state of time, speed and cost of the actual performance of the freight transportation are simulated, which makes it possible to identify and respond in time to the risk caused by interaction between adjacent subjects and objects for transportation. An algorithm to respond to a decrease in speed of transportation is determined.
\end{abstract}

It is substantiated that the efficiency in transportation provides the level of development in transport and logistics system as an infrastructure of a new technological order. The price of these systems generates added value due to speed, inter modality services, drawing up optimal routes for cargo delivery, ensuring full car loads, passage control of goods at all stages of the logistics chain, etc., i.e. through the integration of products and services, considering the dominant global network of production and consumption.

This work is an implementation element of digital formats in the operational activity of railways. The created model implements the "traceability" of information about the movement of cargo traffic in exit routes, generating Fast Date for time-sensitive decision-making process and Smart Date for asymmetric analytics. In contrast to the traditional model of transportation, the proposed solution is based on a mathematical description of all stages of the life cycle of freight (trains), which allows evaluating all costs by type of each process of transportation (movement and idle time) in real time mode. This approach takes into account the "investment" in the formation of value of all enterprises involved in transportation, including the condition and operation of technical infrastructure, locomotives, locomotive crews, wagon and freight facilities employees, and the movers themselves who provide and manage the transportation process.

It is proved that the further growth of the profitability of the transport business is in direct correlation with the increase in the marginal profitability of shippers, and decrease of the transport component in the final price of goods achieved as result of digitizing the process of cargo transportation in the exit routes.

The research methodology is based on the processfunctional approach to describing the life cycle of a freight train, analysis factor for technical and economic characteristics of the transportation process and dynamic modelling of the parameters of significant means of elements affecting the transportation process. The information basis of the study relies on a representative sample of loading and unloading of goods in areas of mass traffic. We have investigated dependent (homomorphic) and independent (singular) pairs in accordance with the time, cost, and technical parameters.

Keywords-asymmetric analytics, digitization of transportation, cost of speed, time, dynamic model, Smart Date.

\section{INTRODUCTION}

Analysis of the studies in the field of efficiency and mobility of product markets highlight the key problem ensuring the transportation's speed growth. Hereupon, the economic description of a "smart" rail system, namely, its ability to generate revenues and optimize transportation costs, is considered fragmentarily. Moreover, there is a definite demand for faster delivery from the shippers, but there is no unambiguous understanding of the technology of economic estimation of speed. The literature presents a number of approaches to the creation of competitive models of rail transportation and their dependence on frequency and speed of traffic, primarily related to highspeed rails (HRS) [1] - [2].

However, there are still no solutions related to the rational behaviour of consumers of transport services depending on time and cost of transportation.

Multiple technological innovations changing the chain of production and consumption form a new value network in the consumer [3] - [4].

Transition from mass production to customized production and from full-cycle enterprises to concentration on competitive advantages will significantly change the transportation service itself: small batches under the order with delivery "precisely in time" for long distances. Eventually, a new business model of transport organizations is shaped. Orientation to 
a specific consumer and the utmost use of the information as a propelling resource, considering the specific features of a specific consumer in a specific place and full use of digital transformation technologies of real business processes, rebuild the whole scheme of relationships in the economy and society. This confirms the idea that the strategy of new business models is completely changed under the influence of the network of transformations of the value proposition of a new transport service [5].

In this regard, the purpose of this work is to form a model of transformation for business processes of freight transportation in the exit routes, taking into account changes in the state of the market and the behaviour of consumers of transport services on it. Ultimately, we have to discover a double effect of speed growth: growth in the profitability of the business in the transportation company and increase in the marginal profitability of shippers due to a decrease in the transportation's price component.

The exit route taken in the study is the most representative for confirming the results of the simulation, since it is formed in areas of mass cargo loading, to the areas of mass unloading. Depending on the capacity of freight traffic, the sending routes are determined by assignment of unloading on one station or section (direct routes) or in the break up of routes in the technical station nearest to the unloading area. Application of Big Data technology allows to process huge amounts of data in real time mode.

Thus, the results of the mathematical description and modelling of cargo transportation in the exit routes proposed in the paper can be presented as part of the overall process of "digitizing" the railway.

\section{MATERIALS AND METHODS}

The solution for the problem of qualitative and quantitative assessment of the actual execution of the process of cargo delivery is possible only with a large array of data on volumes and addresses, timing, speed, intensive procedure and cost of transportation parameters. The reflection of the results is recorded in real time (Tame Date), which allows to quickly make the right decisions in the right place, preventing a rise of losses in the complex process of transportation.

Data processing technology includes three main stages.

In the first stage, the results of a representative sample that characterizes the integrity of freight train processing operations are processed:

- Motion parameters in the composition of the various categories of trains;

- Idle times of trains for various categories at intermediate stations;

- Time for transit operations for various categories of trains at technical stations;

- Step-by-step processing time at technical stations;

- Time of start to end operations.

A traditional factor analysis tool is used to estimate the weight of each factor on the amount's loss of infrastructure resources, rolling stock, and freight transportation costs in general, as well as the formation of a model describing the technical and economic characteristics of the transportation process. The scaled-up scheme of the transportation model is shown in Figure 1.

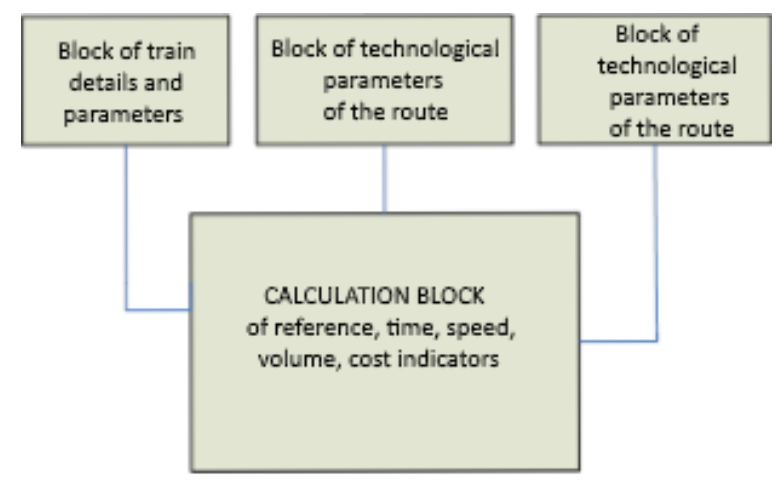

Fig.1. Scheme of transportation model

In this case, the calculation unit includes information:

- Details of the route and the train: cargo, railway, train number, weight, length, station's location, dispatching control subdivision;

- Section length, accumulated passage length;

- Time of formation of the route;

- Time of running, arrival, departure at the station of location;

- Calculation of the time of passage of the section and idle time at the station;

- Identification of idle time at intermediate and technical stations;

- Accumulation of moving and idle time;

- Calculation of technical, sectional, through speed along the section, and accumulated speed;

- Calculation of gross ton-kilometers for the section and in the accumulation, calculation of the car-hours in movement, idle and total;

- Calculation of the actual costs of transit operations during idle time and at technical stations;

- Calculation of operating costs and transportation costs.

The second stage is the dynamic modelling of the parameters of significant factors' weight affecting the transportation process. The purpose of calculation is to determine the costs of the transportation process, "as it is" i.e. in relation to the existing technology of organization of traffic flows and formation of trains and routes of the respective categories. Any change to the existing organization of traffic flows will cause an assessment on the effectiveness of this change in the situation "as it became". The depth and specification of the description of the business processes and its transportation activities of railways must take into account the technology and its changes, regulations and orders governing the organization of infrastructure, traction, and cars. 


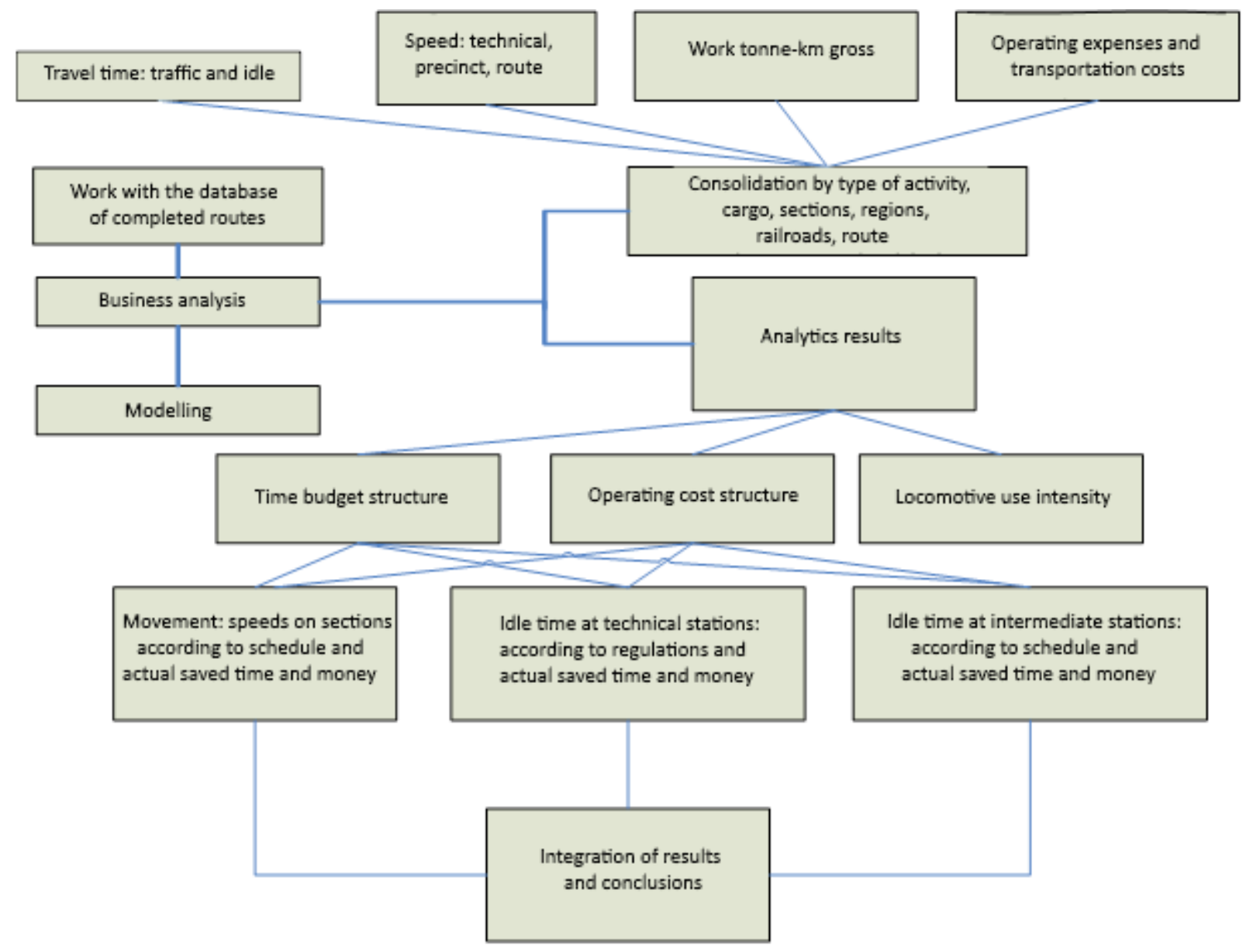

We presume the following dynamic changes in the set of primary models or patterns describing the advantages in the value proposition of the transport service.

a. interactions and relationships between primary models - description of the advantages in the network of values (service business model);

b. processes (predictive maintenance, status tracking);

c. economic interaction between the objects of economic action (resource sharing, instant response) in space and time.

In general, the block diagram of the functional model of freight transportation is shown in Fig.2.

Fig.2. Block diagram of the functional model of freight transportation

The third stage is implemented in the process-functional approach to describing the life cycle of the train. Tonnekilometres gross when moving trains are calculated in two dimensions: by sections and at an approach to the station, taking into account the movement and idle time of the train.

Estimated travel time from the point of departure to the point of destination of the train's destination allows evaluating all expenses by types of economic activity of each transportation process (movement and idle time) in real time mode.

Thus, the cost for idle time per minute for 1 train at technical station $\mathrm{x}_{\mathrm{i}}$ will be: $\delta_{\mathrm{ij}}$ - transit car handling costs using resources of the enterprise $\mathrm{i}$ for all operations $\mathrm{j}$ :

$$
\delta_{i j}=\sum_{k=1}^{K} e_{i j k} * t_{i j k}
$$

$\delta_{i k}$ - transit car processing costs using resources of the enterprise $\mathrm{i}$ for all types of processing $\mathrm{k}$ :

$\delta_{i k}=\sum_{j=1}^{J} e_{i j k} * t_{i j k}$

$\delta_{\mathrm{jk}}$ - transit car processing costs for all operations $\mathrm{j}$ and for all kinds of processing $\mathrm{k}$ :

$\delta_{j k}=\sum_{i=1}^{I} e_{i j k} * t_{i j k}$

$\delta_{i}-$ costs incurred by the enterprise $i$ for transit car processing for all operations $\mathrm{j}$ and for all kinds of processing $\mathrm{k}$ :

$\delta_{i}=\sum_{j=1}^{J} \sum_{k=1}^{K} e_{i j k} * t_{i j k}, j=1 . . J, k=1 . . K$

$\delta_{k}-$ costs of transit car k-type processing for all enterprises $\mathrm{i}$ and for all for all operations $\mathrm{j}$ :

$\delta_{k}=\sum_{i=1}^{I} \sum_{j=1}^{J} e_{i j k} * t_{i j k}, i=1 \ldots I, j=1 \ldots J$ 
$\delta$ - transit car processing costs for all enterprises i, for all operations $\mathrm{j}$, and for all types of processing $\mathrm{k}$ per minute per car:

$$
\delta=\sum_{i=1}^{I} \sum_{j=1}^{J} \sum_{k=1}^{K} e_{i j k} * t_{i j k}, i=1 . . I, j=1 . . J, k=1 . . K
$$

Then the cost of downtime per minute for 1 train at technical station xi will be:

$c_{i}^{m c}=\delta * m$

where $\mathrm{m}$ is the number of the train cars.

This approach takes into account the "investment" in the generation of value by all enterprises involved in the transportation including the condition and operation of the technical infrastructure, locomotives, locomotive crews, wagon and freight facilities employees, and the movers themselves who provide and manage the transportation process.

\section{RESULTS AND DISCUSSION}

The sequence of iterations of the freight transportation functionality over time allowed us to form a mathematical model of value added when processing transit trains at the precinct station. This tool allows you to estimate the cost of time in motion and idle time for the carrier and show the cost of speed for shippers. In this context, we relied on the classification and structure of models for optimizing transport processes "as per schedule", their characteristics and implementation algorithms are proposed by a number of authors during the last ten years [6].

However, almost all of these studies are based on a variety of hypothetical assumptions about the types of railways, types of infrastructure, etc. The development of Big Data technology allowed us to resolve such problems in real time based on real statistics bases on all operations of train preparation and movement, namely, to create a value-added model, which has a number of advantages related to the possibility of monetizing the reduction in transportation time.

The reliability of the results obtained can be confirmed using an integrated approach to the integration of various information environments reflecting operational data and correlating with the accounting and financial systems of the railway company, which are reflected in a number of studies, in particular [7]. As well as studies about the integration of various types of transport systems [8] - [9]. In the development of the discussion, it should be noted a number of studies on the formation of a holistic approach to the use of IIoT (Industrial Internet of Things) technology, allowing to carry out advanced monitoring of assets and operations of railway companies, expand the functionality of Passenger and Freight Information Systems (PIS/FIS), Train control systems, etc. A number of authors (Fraga-Lamas, P., Fernández-Caramés, T.M., Castedo, L.) believe that it is namely IIoT that ensure credibility of decisions to improve the efficiency of the transportation process [10].

In this study, the procedures and results of the Big Data mining. Hereupon, a number of authors, in particular Song, R., Xue, X., propose using neural networks in the processing of large databases. [11]. Their use will undoubtedly significantly improve the forecast estimation of the modelling of the cargo transportation process and will reduce the number of assumptions having a probabilistic nature.

An important part of the scientific discussion is devoted to the technical support of modelling various scenarios for the organization of rail transportation, in particular, the organization of wireless systems in the management of railway passenger transport systems, which is undoubtedly important when organizing mixed, passenger, and freight traffic on a single infrastructure [12].

Despite the breadth of discussion about various directions of transport processes modelling, value measurement research of the processes of goods transportation in real time is not enough. We can note more general research related to maximizing the cost of transport projects when using digitalization technologies, in particular Cruz, C.O., Sarmento, J.M. [13]. Valuation procedures of the cargo traffic processing scenarios for freight trains and at the stations using operating work simulation are described by Schneider M, Nießen N. [14].

Among the fundamental papers on transport modelling, the research by Anna Nagurney and John F. Smith, University of Massachusetts, Amherst, Massachusetts USA should be highlighted [15]. In particular, the description of various models of traffic flows and the process of their consolidation.

This once again confirms the importance and relevance of tracking, linking and modelling on functions and processes of costs simultaneously incurred by all railway departments at each stage of technological redistribution and reliably estimation of the value-added transportation cost.

\section{CONCLUSIONS}

The overall result of the study should be considered as a dynamic model of railway transportation of goods in exit routes, allow you to determine the added value of the technical, district and route speed of a freight train across its entire route in real time. With the help of an asymmetric analytics tool based on graph theory, this study will be conducted in the direction of analysing the time budget of completed routes, taking into account all factors affecting it, considering the intensity of locomotive use and speed [16] - [17].

With further development of the model, its economic description and the "traceability" of the movement's speed in the tariff, it is possible to obtain an estimate on the effect of speed and its influence on the growth of commodity markets.

The authors state that:

1. They have no conflicts of interest;

2. This article does not contain any research involving human subjects as research objects. 


\section{REFERENCES}

[1] O. Álvarez-SanJaime, P. Cantos-Sanchez, R. MonerColonques, J.J. Sempere-Monerris "A model of internal and external competition in a High Speed Rail line" Economics of Transportation, 2015, vol. 4, Iss. 3, pp. 178-187.

[2] R. Vickerman "Can high-speed rail have a transformative effect on the economy?" Transport Policy, 2018, vol. 62, pp. 31-37.

[3] V. Allee The Future of Knowledge. USA: ButterworthHeinemann, 2002.

[4] C. Parolloni The Value Net: A Tool for Competitive Strategy. New York: Villey, 1999.

[5] M.W. Jonson, M.C. Christensen, H. Kadermann "Reinventing your business model", Harvard Business Review, December 2008 [Online]. Available: https://hbr.org/2008/12/reinventingyour-business-model. [Accessed: Jan. 10, 2019].

[6] P. Vilela, M. Cachoni, A. Vieira, L. Christofoletti, Train circulation planning: Quantitative approaches, Conference: 2017 Joint Rail Conference. Philadelphia, Pennsylvania, USA, April 4-7, 2017. [Online]. Available: https:// www. scopus.com/inward/record.uri? eid=2-s 2.0 $5026810165 \&$ doi $=10.1115 \% 2$ fJRC2017-2223\&partnerID $=40$ $\& m d 5=5$ badb9c5064e86e8b7f16f70e8667a16. [Accessed: Nov. $10,2017]$.

[7] I.V. Bychkov, A.L. Kazakov, A.A. Lempert, D.S. Bukharov, A.B. Stolbov "An intelligent management system for the development of a regional transport logistics infrastructure", Automation and Remote Control, 2016, vol. 77, Iss. 2, pp. 332-343. [8] Y. Ma, D. Chang, F. Wang "Integrating business processes of container sea-rail combined transport", International Journal of Internet Manufacturing and Services, 2019, vol. 6, No 1, pp. 48-63.

[9] L. Heilig, S. Voß, "Information systems in seaports: a categorization and overview", Information Technology and Management, 2017, vol. 18, Iss. 3, pp. 179-201.
[10] P. Fraga-Lamas, T.M. Fernández-Caramés, L. Castedo “Towards the internet of smart trains: a review on industrial IoT-connected railways", Sensors (Basel), 2017, vol. 17, no. 6, no. 1457, pp. 1-44. [11] R. Song, X. Xue, "Freight volume forecast based on improved radial basis function neural network", Boletin Tecnico, 2017, vol. 55, iss. 5, pp. 419-423.

[12] L. Azpilicueta, J.J. Astrain, P. Lopez-Iturri, F. Granda, C. Vargas-Rosales, J. Villadangos, A. Perallos, A. Bahillo, F. Falcone "Optimization and design of wireless systems for the implementation of context aware scenarios in railway passenger vehicles", IEEE Transactions on Intelligent Transportation Systems, 2017, vol. 18, iss. 10, pp. 2838-2850.

[13] C.O. Cruz, J.M. Sarmento "Maximizing the value for money of road projects through digitalization", Competition and Regulation in Network Industries, November 27, 2018. [Online]. Available: https://doi.org/10.1177/1783591718811436 [Accessed: Jan. 18, 2019].

[14] M. Schneider, N. Nießen "Minimising economic losses due to inefficient rescheduling", Journal of Rail Transport Planning \& Management, 2016, vol. 6, iss. 2, pp. 128-140.

[15] A. Nagurney "Mathematical models of transportation and networks (Refereed Encyclopedia Article)" Mathematical Models in Economics, Encyclopedia of Life Support Systems, 2007 [Online]. Available: http://works.bepress.com/anna nagurney/191/ [Accessed: Jan. 15, 2019].

[16] L. R. Ford, D. R. Fulkerson "Maximal flow through a network", Canadian Journal of Mathematics, 1956, vol. 8, pp. 399-404.

[17] J. R. Evans, E. Minieka Optimization algorithms for networks and graphs. 2nd ed. New York: Marcel Dekker, 1992. 